\title{
Analysis of Network Economy's Impact on International Trade and Strategy
}

\author{
YANG Wenwen ${ }^{1, \text { a }}$ \\ ${ }^{1}$ Jiangxi college of foreign study, NanChang 330099, China \\ a yangwenwen@126.com
}

Keywords: Network Economy; Multinational Corporation; Intra-firm Trade; Cost structure

\begin{abstract}
Since the middle of the 20th century, multinational companies have experienced great development on the quantity and the trade scale under the dual influence of globalization and informationization. As the main body of international business, multinational companies' foreign direct investment led to large flow of the final products, intermediate products, technology and services on a global scale and the flow takes its internal trade as medium. Internal trade of the multinational company lead to international trade transfer and international industry restructuring, which played a very important role in accelerating economic globalization.
\end{abstract}

\section{Basic theory of network economy}

\section{Connotation of the network economy}

Network economy can be summarized as a kind of new economic form based on computer network with modern information technology as the core. It not only refers to the rise of information technology industry and rapid growth that takes computer as the core, but also include the high and new technology industry's rise and rapid development on the basis of modern computer technology and profound revolutionary change and leap development caused by high and new technology in promotion and application of the traditional industry. [1]It is actually advanced economy form produced on the basis of traditional economy after modern information technology improves. After deepening the study and understanding of the knowledge economy, it is easy to find that though at present people have a variety of descriptions of future economic, such as knowledge economy and information economy, industrial economy, new economy, the attention economy, etc., their base is the same, that is the computer and the computer network, especially the international Internet network.

\section{Characteristics of the network economy}

As a kind of new economy, network economy, network economy has various characteristics result from the effect of information network compared with the previous traditional economic.

The network economy is round-the-clock operation of economy. Because the information network is in running 24 hours a day, so the economic activity based on the network of rarely restricted by the time factor, the all-weather continuous.

Network economy is economic globalization. Because the whole world is changed into a "global village" by information network, the geographic distance tends to be irrelevant, economic activity based on the network reduced the space factors to the minimum, making whole economic globalization greatly accelerated, the world economic interdependence unprecedented strengthening.

The network economy is "direct" economy decreased in the middle level role. With the development of network economy trend, the organization structure changes in the direction of thin, producers and consumers in the network endpoint of can directly connect. Middle level loses the necessity of existence for the producers and consumers can meet with each other. 


\section{Construction of complex network theory and international trade network}

\section{Introduction to the theory of complex networks}

\section{1) Research background of complex network theory}

Complex networks theory is considered to be one of the most important subjects in the 21st century, Application of the complex network theory and in the natural, engineering, biological and social and other fields have mushroomed to explosion. [2]However, because of the complex network method to deal with mass data and information belong to the category of macroscopic statistical methods, and large-scale relational data acquisition in the field of economic management in objectively exist great difficulties, so this method in the application has been restricted in the field of economic management. Although some scholars have tried to apply complex network analysis method applied to the field of economic management, the related research is few.

\section{2) Basic measure index of the complex network}

Complex network is composed of nodes and edges. If the network edge has no direction, then it is called the undirected network, otherwise known as directed network. According to the rules of the network connection on the side, and rules of complex networks it can also be divided into network, random networks and scale-free networks.

(1)Distribution of degree. Degrees are simple and important concept in the node properties. Node $i$ and $k_{i}$ are defined as the number this degree connected with other nodes. Nodes in the network is divided into the input degrees and the output degree. The output degree of node refers to the number of edges from the node to other nodes, the input degree of node refers to the number of from the edge of the points to the other node. Intuitively, the greater the degree of a node, in a sense, means that the node is more " important ". [3]The average of degree of all nodes in the network is referred to as $\langle\mathrm{k}\rangle$, it reflects the average connection density of the network.

(2) The average path length. The distance $d_{i j}$ between two nodes $i$ and $j$ in the network is defined as the connection of the two nodes number of edges on the shortest path, the distance between any two nodes in a network of maximum value is called the diameter of the network. Average path length $\mathrm{L}$ of Network is defined as the average of the distance between any two nodes, namely:

$$
L=\frac{1}{\frac{1}{2} N(N+1)} \sum_{i \geq j} d_{i j}
$$

(3) Clustering coefficient: generally, assume in the network, a node $i$ have $k_{i}$ edges and other nodes connected to it, the $k_{i}$ is called neighbor of node $i$. Clearly, between nodes there may be most $k_{i}\left(k_{i}-1\right) / 2$ sides.

$$
C_{i}=2 E_{i} /\left(k_{i}\left(k_{i}-1\right)\right)
$$

(4) Affinity of node

Node affinity to describe the similarity between the nodes is expressed in "zoom in" multiples of node degrees, defined as:

$$
k_{A, i}=\frac{1}{k_{i}} \sum_{J \in \psi(i)} k_{j}
$$

\section{International trade building and characteristics of complex networks \\ 1) international trade construction of complex networks}

In the network, if the node on behalf of the state, trade links between edge on behalf of the state, make up international trade networks. [4]According to different research purposes, the international trade network can build into the undirected network, also can build into a directed network, can be weighted network, also can be the right to network.

(1) Undirected network: In the international trade network, if you don't consider the direction of the trade, the formation of the network for undirected network. Specific and can be divided into undirected and unweighted network, and undirected and weighted network. 
Undirected and unweighted network: in undirected and unweighted international trade networks, adjacency matrix $\mathrm{A}$ is symmetric matrix between countries, adjacency matrix A of element $a_{i j}$ said whether $i$ and $j$ countries trade happened in A certain period of time, that is: if don't happen trade then $a_{i j}=0$, if there is then $a_{i j}=1$, and $a_{i j}=a_{j i}$.

Undirected and weighted network: in undirected and weighted the international trade network, trade relations between countries by weighted adjacency matrix $\mathrm{w}, \mathrm{w}$ is still symmetric matrices. The weighted connection matrix w elements $W_{i j}$ said total trade between the countries in a certain period of time, as the edge weights of network, and have $W_{i j}=W_{j i}$.

(2) Directed network:

If the direction of the edge in the international trade network by the importer, exporter, namely, define the direction of the edge is in line with the flow of money in international trade and international trade are formed to the network, the directed edge is also called arc.

International trade is to network and can be divided into the following two kinds:

Directed but unweighted network: in the directed but unweighted international trade network, trade relations between countries can be shown with adjacency matrix $A^{E}$. $A^{E}$ is symmetric matrix, its elements value of 1 or 0 , respectively show whether there is export of $i$ to country $j$ in a certain period, and clearly $a_{i j}^{E}=a_{j i}^{l}$

Directed and weighted network: in the directed and weighted international trade network, trade relations between countries with weighted adjacency matrix deposition $W^{E}$ or $W^{l}$. $W^{E}$ and $W^{l} \mathrm{~s}$ describe the export and import trade relations between countries. The elements of weighted adjacency matrix deposition $W^{E}$ or $W^{l}$ is the arc weights of the network, said the export trade of $\mathrm{j}$ countries in a certain period of time, apparently have $W_{i j}^{E}=W_{j i}^{l}$.

\section{2) Description of the characteristics of international trade networks}

According to the research of the financial crisis in the international trade network transmission, the purpose of considering the feasibility of the research, papers in the subsequent section, select only the part of the description of the basic indicators and methods of the complex network characteristics, the indicators and methods can be divided into two kinds, one kind is to describe characteristics of node index and method, one kind is describe the network characteristics of the overall index and methods.

International trade network node characteristics indicators are:

(1) the node degrees

The degree of nodes is defined as $k_{i}=\sum_{j \in \Re(i)} a_{i j}$

(2) the right of node

Node degree only reflects a country's trading partners, is not able to fully reflect the country's influence in the international trade network "a nation's influence in the international trade network besides affected by how much trade partner, also depends on the size of the volume of trade, therefore, need to use trade right of compute nodes.

\section{Measures should be taken to cope with the international trade}

\section{Further expand the country's exporters}

In the production of manufactured goods, part of the raw materials need to be imported from other countries or multinational country, at the same time, some products exported to other countries and multinational country, some of them are from multinational company internal trade. Since multinational company internal trade constitutes a part of the host country commodity import and export, by giving the multinational company internal trade policy guidance, you can expand the export of the host country. In many developing countries, for example, foreign companies, many are carry on the processing trade, imports of raw materials from abroad, the product sells back abroad, 
and multinational companies holding the raw materials and products in and out of the channel, in a into a multinational company can gain significant benefits, and host countries only get a small amount of processing fee. [5]Therefore, if the developing countries to adjust and standardize multinational companies in its own to the processing trade, such as encouraging in the domestic procurement of raw materials and spare parts, the proportion of export products, etc., can further expand the exports of developing countries.

\section{Monitor the transfer price in the trade}

Multinational companies set up wholly owned or joint venture in the host country to do a large number of international trades, most of which belong to internal trade and this make the prices transfer becomes possible.

In view of the multinational company internal trade in the use of the transfer price to the interests caused significant damage to the host country and its domestic enterprises, developing countries should be monitored by to minimize the losses. In terms of monitoring shall be implemented for the transfer price, developed countries have taken some measures, and introduced the related law, some countries have prevent the transfer price together for the interests of the state and considerable achievements had been achieved. First of all, increase tax and audit personnel professional quality and the ability to verify the transfer price, strengthening the customs' supervision on inbound and outbound products market price and censorship, investigate of the unreasonable price in strict accordance with the rules of customs valuation, levy duties; Secondly, establish a national database transfer price, collecting all kinds of equipment at home and abroad, the price of raw materials, products, information such as the national tax rates and special tax regulations and provide a basis to verify the price; Thirdly, developing countries can draw lessons from the practice and experience of developed countries such as America in the implementation of tax rate and tariff rate in order to avoid the use of transfer pricing.

\section{Improve the ability of independent innovation to ensure the safety of industry and economy}

Support of multinational company in the international competition is technology and especially high new technology, so they will not easily to transferred to foreign countries. Therefore, in developing countries in technology and capital introduction, first of all, they should pay attention to the introduction of appropriate technology, as some are not affected by a few multinational company monopoly technology, the introduction cost is low, and can be used to fill the domestic blank or to transform traditional industries, make it become the strong support of new and high technology industries. Second, pay attention to changing from transplantation mainly into technology absorption, from the state introduction primarily introduced into enterprise primarily, establish a scientific incentive mechanism, and improve enterprise technology research and development capabilities, so as to improve the efficiency of the technology import. Thirdly, enterprises should attach great importance to the introduction of absorption and innovation of technology, the development of high-tech industries, and take the way of the combination between the independent development and technology transfer, which is an important link for the developing country industry security and economic security.

\section{Summary}

The continuous improvement of the network economy and the rising popularity of e-commerce application have brought unprecedented opportunities to the development of international trade, but it also brings new challenges. For the enterprise, apply e-commerce to international trade activity is a kind of investment, which has certain risk. Therefore, enterprises need to further analyze and forecast the cost to assist corporate decision makers in clear network application of the specific objectives and functions in international trade.

\section{References}

[1] Lin Xiaoyan, Wang Hongmei. Course of technology economics. Economic management press. 
2005(11).

[2] Wang Zhile. The new trend of development of the multinational companies in China [M]. Beijing: Xinhua publishing house, 2003.

[3] Sun Guohui. Multinational company internal trade research [M]. Jinan: Shandong people's publishing house, 2002.

[4] Qiu Guodong. The company development strategy [M]. Beijing: people's publishing house, 2005.

[5] Yu Wenqing. The concept of the foreign trade enterprise cost and the meaning of cost control. Liaoning administrative college journal. 2005(4). 